\section{Popliteal pterygium syndrome: A rare syndrome}

Sir,

This report describes the clinical features of an adolescent female who presented to us for popliteal webbing and hence difficulty in walking and operated cleft lip and palate with lower-lip pits. She was diagnosed as popliteal pterygium syndrome (PPS) which is a rare autosomal dominant congenital disorder described by Trelat in 1869 that includes orofacial, cutaneous, musculoskeletal and genital anomalies. ${ }^{[1,2]}$ This syndrome has some features in common with Van der Woude syndrome, also inherited as an autosomal dominant condition. ${ }^{[3]}$ The minimum diagnostic criteria for PPS are any three of the following: cleft lip/palate, popliteal pterygium, paramedian lower-lip pits/sinuses and genital and toenail abnormalities. ${ }^{[4]}$ Lower-lip pits, which may resemble a depression or furrow, represent the opening of a tract leading from a mucous gland embedded in the lip. ${ }^{[3]}$ Lip pits may be divided into three types according to their location: commissural, midline upper lip and lower lip. ${ }^{[5]}$ The genital anomalies include cryptorchidism and bifid scrotum in males and hypoplastic labia majora and uterus in females. Various hypotheses include a primary microvascular abnormality with associated oedema leading to disturbance of epithelial tissues resulting in adhesion formation ${ }^{[6]}$ excessive epithelial growth leading to fusion and secondary mesenchymal involvement, ${ }^{[7]}$ a primary collagen defect ${ }^{[8]}$ or a loss of programmed cell death. ${ }^{[9]}$

We present this case of a 14-year-old girl who had difficulty in walking for 12 years. She was operated for cleft lip and palate at 2 years of age. Her two paternal uncles had similar features of this syndrome, but her parents were healthy and unrelated. There was no significant antenatal history. Her developmental and menstrual histories were normal. She had extensive popliteal webs, extending from the ischial tuberosities to the Achilles tendons as a fibrous cord, and was unable to extend her legs fully with tight Achilles tendon with ankle in equinus [Figures 1 and 2]. The genitalia were involved with hypoplasia of the labia majora. She had a surgical scar of a repaired cleft lip and palate and the lower-lip pits were present [Figure 3]. Magnetic resonance imaging of the right distal thigh and leg revealed diffuse fibrofatty changes in the muscles representing mild fatty atrophic changes and associated 


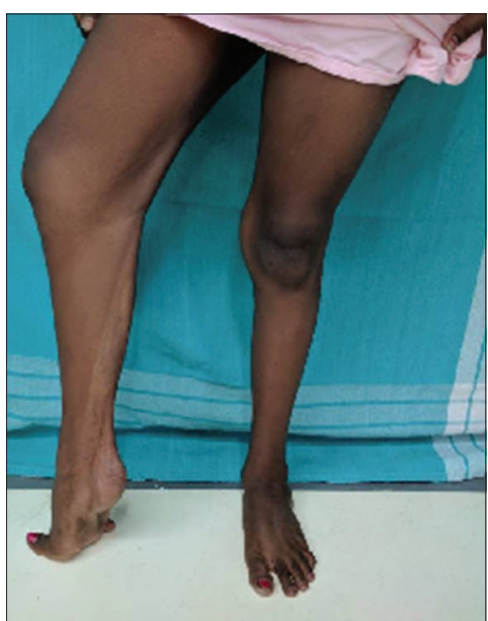

Figure 1: Pre-operative photograph (anterior view)

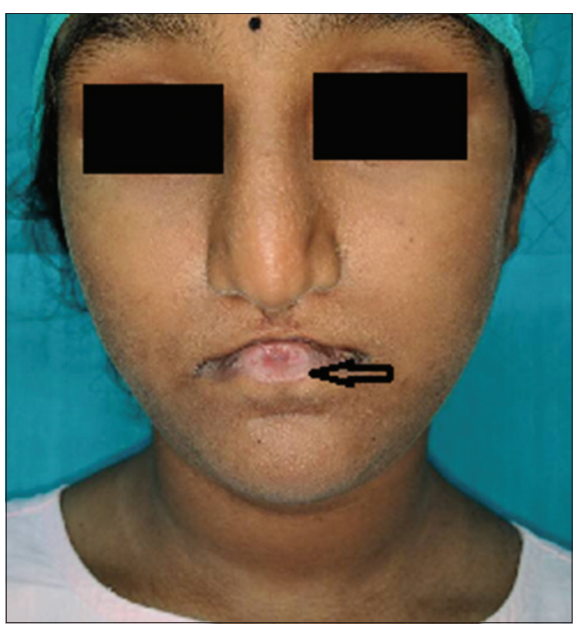

Figure 3: Photograph showing the operated cleft lip scar with lower-lip pits - black arrow

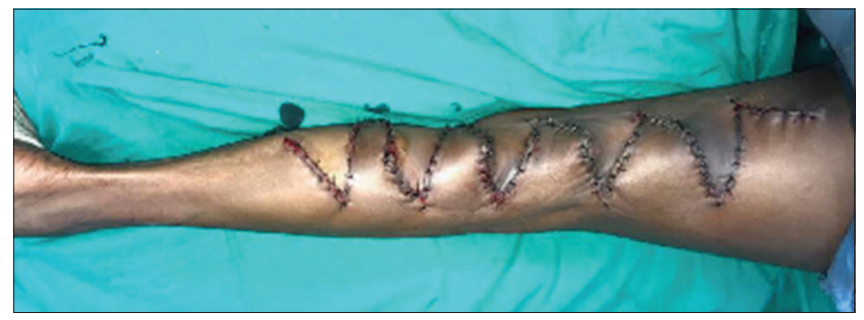

Figure 5: Immediate post-operative picture

muscular dystrophy with normal neurovascular structures [Figure 4]. We proceeded with multiple $Z$-plasty correction of the popliteal band under general anaesthesia in prone position [Figure 5]. She was put on a plaster of Paris slab in the post-operative period for 1 week. The post-operative period was uneventful with suture removal on the $12^{\text {th }}$ post-operative day and the patient was on regular follow-up for 2 months [Figure 6].

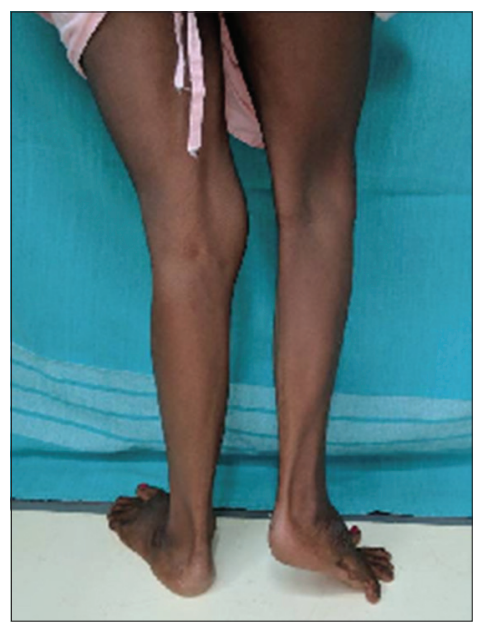

Figure 2: Pre-operative photograph (posterior view)

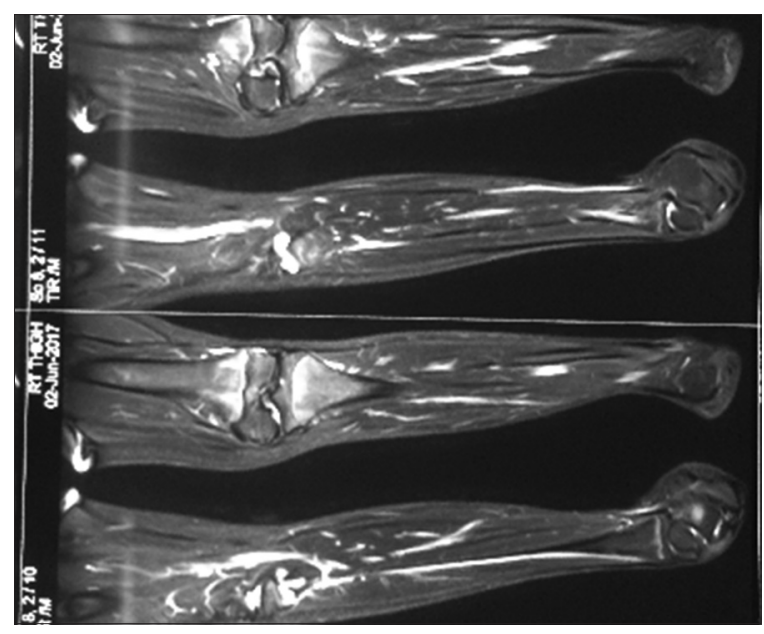

Figure 4: Magnetic resonance imaging showing fibrofatty changes in the muscles of the right leg and thigh with muscular dystrophy

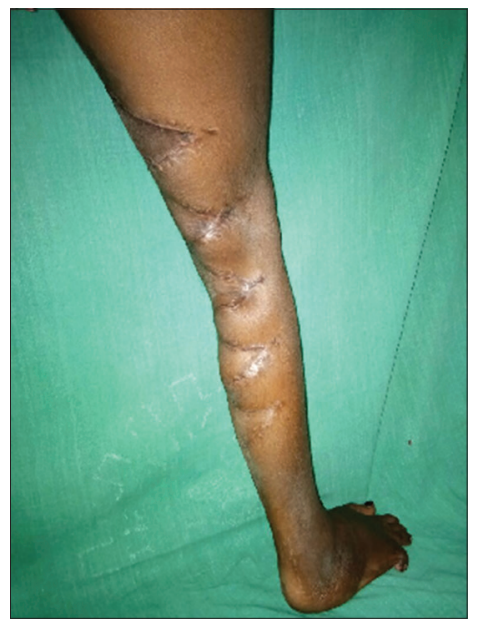

Figure 6: Two months' post-operative picture

PPS is a unique anomaly and hence underreported. A careful examination of the patient may identify lip pits in addition to the popliteal web. Meticulous 
physical examination of the family members and genetic counselling is also required for these patients.

\section{Declaration of patient consent}

The authors certify that they have obtained all appropriate patient consent forms. In the form the patient(s) has/have given his/her/their consent for his/her/their images and other clinical information to be reported in the journal. The patients understand that their names and initials will not be published and due efforts will be made to conceal their identity, but anonymity cannot be guaranteed.

\section{Financial support and sponsorship}

Nil.

\section{Conflicts of interest}

There are no conflicts of interest.

\section{Surya Rao Rao Venkata Mahipathy, Alagar Raja Durairaj, Narayanamurthy Sundaramurthy, Manimaran Ramachandran}

Department of Plastic and Reconstructive Surgery, Saveetha Medical College and Hospital, Kanchipuram, Tamil Nadu, India

Address for correspondence: Dr. Surya Rao Rao Venkata Mahipathy, Department of Plastic and Reconstructive Surgery, Saveetha Medical College and Hospital, Thandalam, Kanchipuram - 602 105, Tamil Nadu, India. E-mail: surya_3@hotmail.com

\section{REFERENCES}

1. Melnick M, Bixler D, Fogh-Andersen P, Conneally PM. Cleft lip+/-cleft palate: An overview of the literature and an analysis of Danish cases born between 1941 and 1968. Am J Med Genet 1980;6:83-97.
2. Trelat $U$. On a very rare conformation defect of the lower lip J Med Chir Prat 1869;40:442-5.

3. vanDerWoudeA. Fistula labii inferioris congenita and its association with cleft lip and palate. Am J Hum Genet 1954;6:244-56.

4. Escobar V, Weaver D. Popliteal pterygium syndrome: A phenotypic and genetic analysis. J Med Genet 1978;15:35-42.

5. Nagore E, Sánchez-Motilla JM, Febrer MI, Serrano G, Bonillo J, AliagaA, et al. Congenital lower lip pits (Van der Woude syndrome): Presentation of 10 cases. Pediatr Dermatol 1998;15:443-5.

6. Hall JG, Reed SD, Rosenbaum KN, Gershanik J, Chen H, Wilson KM, et al. Limb pterygium syndromes: A review and report of eleven patients. Am J Med Genet 1982;12:377-409.

7. Gassner I, Müller W, Rössler H, Kofler J, Mitterstieler G. Familial occurrence of syngnathia congenita syndrome. Clin Genet 1979;15:241-4.

8. Hartwig NG, Vermeij-Keers C, Bruijn JA, van Groningen K, Ottervanger HP, Holm JP, et al. Case of lethal multiple pterygium syndrome with special reference to the origin of pterygia. Am J Med Genet 1989;33:537-41.

9. Hunter A. The popliteal pterygium syndrome: Report of a new family and review of the literature. Am J Med Genet 1990;36:196-208.

This is an open access journal, and articles are distributed under the terms of the Creative Commons Attribution-NonCommercial-ShareAlike 4.0 License, which allows others to remix, tweak, and build upon the work non-commercially, as long as appropriate credit is given and the new creations are licensed under the identical terms.

\begin{tabular}{|l|l|}
\hline \multicolumn{2}{|c|}{ Access this article online } \\
\hline Quick Response Code: & Website: \\
\hline & www.ijps.org \\
\cline { 2 - 2 } & DOI: \\
\hline
\end{tabular}

How to cite this article: Venkata Mahipathy SR, Durairaj AR, Sundaramurthy N, Ramachandran M. Popliteal pterygium syndrome: A rare syndrome. Indian J Plast Surg 2018;51:248-50.

๑ 2018 Indian Journal of Plastic Surgery | Published by Wolters Kluwer - Medknow 